\title{
The Significance of Secondary Metabolites for Interactions between Plants and Insects ${ }^{1}$
}

\author{
Adolf Nahrstedt ${ }^{2,3}$ \\ ${ }^{1}$ Plenary Lecture given at the $36^{\text {th }}$ Annual Congress of the Society for Medicinal Plant Research, Freiburg, Sept. 1988. \\ ${ }^{2}$ Institut für Pharmazeutische Biologie und Phytochemie, Westf. Wilhelms-Universität, D-4400 Münster, \\ Federal Republic of Germany
}

Received: October, 25, 1988

\section{Abstract}

Several levels of plant/insect-interactions on the basis of secondary compounds are described and illustrated with some examples. Plant secondary substances, originally accumulated for defense, are tolerated by adapted insects. Hence, plants have had to accumulate new secondary constituents during evolution for their protection. Adapted insects are able to use former plant repellents as attractants and, after collection or sequestration, as allelochemicals for several purposes. Some insects produce substances for defense that are structurally typical plant secondary compounds; in one case biosynthesis and uptake from the host of the same substances occurs. It is concluded that secondary metabolites are of great significance for the coexistence and biochemical development of plants and insects.

\section{Introduction}

Although a comprehensive overview on functions of chemical and morphological features of plants in their relation to herbivores was published by Stahl in 1988 (1), plant/ animal-interactions on the basis of their secondary metabolites were nearly totally ignored and were not accepted by more than one generation of biologists. This situation was changed when in the late nineteen fifties a series of review papers appeared; a selection of excellent reviews (2-9) includes the first of Fraenkel (2) which had again revived this topic. It is evident from the diversity of authors that they represent several disciplines of the natural sciences, showing that work in this field requires interdisciplinary cooperation. Two papers published recently $(8,9)$ are excellent summaries of the present knowledge. In addition to the review articles, several monographs have been published (10-14), including one textbook in German (14). Of these the comprehensive collection of articles in (12) can already be regarded as a classic.

In the light of all these excellent summaries, it is not the aim of this paper to present another review on all the hitherto detected interactions between plants and insects in which secondary substances are involved. It is my intention to give an impression of the several levels that exist, on the basis of secondary substances, of the relationshiphs between plants and insects; this will be illustrated by a few selected examples.

\section{Plant Secondary Substances Function as Protective Agents}

It is well known that plants are used as food sources by insects. If there were no defense against herbivores, plants would already be extinct. Plants have therefore evolved numerous barriers against herbivores $(15,16)$, such as competitive production of biomass, morphological features, disappearance out of space and time, and the so-called secondary metabolites, which function as protective agents against herbivorous insects. It is now widely accepted that the diversity of secondary compounds that are accumulated is the result of the need for chemical defense, and that plants have accumulated these substances under the pressure from herbivores. Two recent results will again underline this, using preferentially substances that are also active constituents of medicinally used plants.

Sesquiterpene lactones, such as parthenin and tenulin (Scheme A), obtained from Asteracean plants, are well known as anti-inflammatory agents (17) and inhibitors of tumor growth (18). For some insects (e.g. Ostrinia nubilalis, Heliothis zea), they have strong antifeedant activity $(19,20)$ in concentrations far below the actual concentration in the plant tissue: tenulin inhibits feeding at $3 \mu \mathrm{mol}$ per $\mathrm{g}$ fresh weight, but its concentration in Helenium amarum exceeds $15 \mu \mathrm{mol}$ per $\mathrm{g}$ fresh weight (20). This explains why insects that usually feed on the Asteraceae, or that are highly polyphagous and thus tolerate many different compounds, do not feed on plants accumulating such substances. The result is that these plants are protected against a wide group of potential herbivores. It had been shown in earlier studies that the $\alpha$-methylene- $\gamma$-lactone and the $\alpha, \beta$-unsaturated carbonyl groups are the active parts of

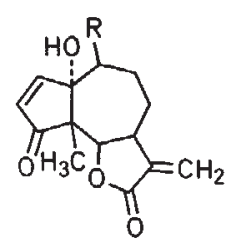

parthenin $\left(\mathrm{R}=\mathrm{CH}_{3}\right)$

Scheme A

\footnotetext{
${ }^{3}$ Dedicated to Professor Dr. R. Robert Hegnauer, Leiden, on the occasion of his $70^{\text {th }}$ birthday on August 1, 1989.
} 
the molecules which react with nucleophiles (21). For tenulin, the significance of the second active site is supported by the result that its addition product with cysteine (Scheme A) exhibits a much reduced antifeedant activity (20). It is interesting, but not surprising, that the same reactivity which is responsible for pharmacological and allergenic (22) properties, also causes strong deterrence of insect herbivores.

It is well known that the large white butterfly (Pieris brassicae) oviposits on plants that contain glucosinolates, which themselves release mustard oils. However, Cheiranthus and Erysimum species are not accepted, although they contain the classical oviposition cues, the glucosinolates. Recent findings of Rothschild and coworkers (23) have shown that strophanthidin-glycosides (probably cymarin and similar compounds) act as oviposition deterrents upon contact. These compounds are located on the surface of the leaves, thus they are easily detected by the females of the large white butterfly which drum with their forelegs on the leaves before oviposition. If (by chance) oviposition occurs on one of these plants, none of the young larvae survive beyond the second instar as death is caused by contact with the cardiac glycosides (23). Thus, both these Brassicaean species gain protection from a predator that is normally specialized for Brassicacean plants. One may speculate that Cheiranthus and Erysimtum species have evolved the potential for production of cardenolides under the pressure of the large white butterfly or its ancestor, which itself is adapted to the common deterrent of the Brassiaceae, the glucosinolates; to our knowledge no data as yet exist in support of this proposition, but it may indicate that chemical diversification can well be the result of ecological pressure.

\section{Adapted Herbivorous Insects Tolerate Plant Secondary Compounds}

The above already indicates that no defense line is absolute and it is therefore not surprising that some insects have overcome chemical protection of plants, in that plant secondary substances, normally repellents, are tolerated by adapted herbivorous insects.

Cardiac glycosides, similar to those which are toxic to the larvae of the large white butterfly, are ingested without harm by the monarch butterfly (Danaus plexippus) and the common milkweed bug (Oncopeltus fasciatus), and are even stored by these insects $(24,25)$. It was shown recently that both insects possess a sodium/potassium-ATPase that is insensitive to cardenolides $(26,27)$, thus allowing the animals to handle these toxic plant constituents and to settle on plants which are toxic to non-adapted insects.

Linear furanocoumarins are known to be toxic for insects, expecially in the presence of ultraviolet light (28). However, some insects, such as, for example, the larvae of the black swallowtail (Papilio polyxenes) and the full armyworm (Spodoptera frugiperda), successfully feed on plants of the Umbelliferae that contain high levels of these photosensitizers (29). Both insects are able to cleave the furan ring to give photobiologically inactive products, probably via an epoxide intermediate (Scheme B). This detoxification occurs very rapidly in the midgut tissue and is the same as that observed in some mammalians (29). The potential of detoxification of plant deterrents of course opens new ecological niches for such metaboli-

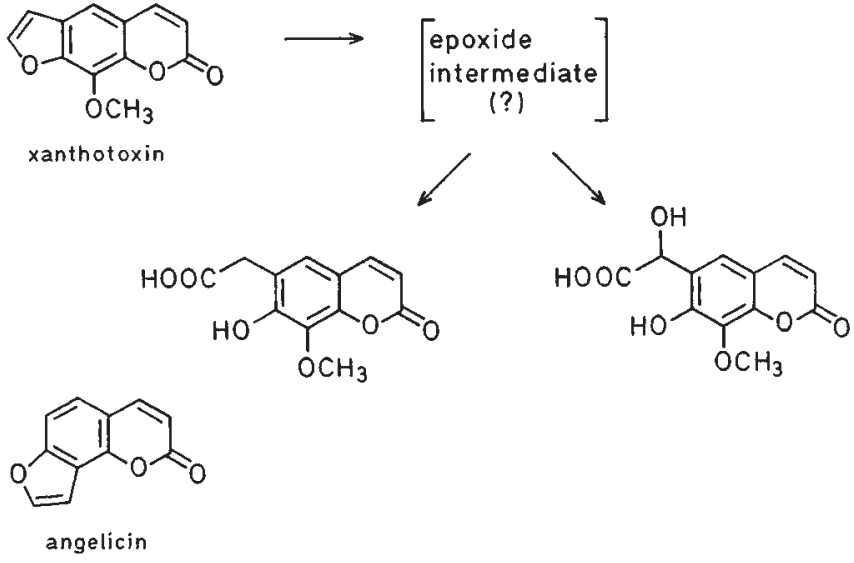

Scheme B

cally successful insects. How does the plant answer this challenge? Although the black swallowtail tolerates linear furanocoumarins, its development is drastically reduced by angular furanocoumarins such as angelicin (28), that cannot be metabolized to products comparable to those derived from the linear furanocoumarins (Scheme B). Several of these observations have led to the assumption that, in the coevolutionary system of the coumarin-containing plants and their predatory caterpillars, some plants have shifted their chemistry form the linear to the angular furanocoumarins, thus affording protection again against predators which had previously been adapted to the linear furanocoumarins (28).

Another example of plants avoiding their metabolically successful predators may be the production of pheromones and hormones which keep the predator at a certain distance or influence their development by keeping the predator's population small. For example, the wild potato ( $\mathrm{Sol}$ anum berthaultii) produces a sesquiterpene, $(E)$ - $\beta$-farnesene (Scheme C), in special glandular hairs, the so-called type-Bhairs (30). The sticky secretion is not surrounded by a cell wall, thus a head space concentration occurs above the leaf of several tens of nanograms of farnesene. This compound is also the alarm pheromone of many aphid species which feed successfully on many plants including cultivated potatoes (Solanum tuberosum) that lack the type-B-hairs and consequently lack farnesene. However, if wild potatoes are presented to polyphagous aphids (Myzus persicae), they keep away at a distance of $1-3 \mathrm{~mm}$, and they behave similarly, if other plants are experimentally contaminated with $(E)-\beta$-farnesene (30). Thus, the wild potato is fortunate in producing and releasing a secondary compound that is used by its predator to inform the colony about a dangerous situation. This is rather sophisticated as it would be difficult, if not impossible, for the aphids to overcome the false alarm of the plant's $\beta$-farnesene. It is of interest that structurally very similar compounds do act as juvenile hormones. Thus, juvenile hormone III (Scheme C), was isolated from a Cyperacea (Cyperus iria) and is the cause of underdevelopment of adults of a grasshopper (Melanoplus sanguinipes) whose larvae have fed on Cyperacean grasses (31). The advantage for the plant is that the juvenile hormone reduces the predator's population.

From such examples one can well imagine that there occurs a biochemical ping-pong-mechanism during evolution of plants and their associated insects, that is caused 
<smiles>C=CC(=C)CC/C=C(\C)CCC=C(C)C</smiles>

(E) - $\beta$-farnesene

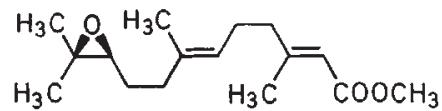

juvenile hormone III
Scheme C

by chemical and/or metabolical ecological pressure, performed by both groups of organisms; a pressure which then leads to new levels of resistance in plants, followed by biochemical specialization of their insects, followed by accumulation of new secondary compounds by plants, and so on.

\section{Plant Repellents Serve as Attractants for Insects}

If an insect is able to detoxify a certain plant deterrent, the next step for its successful accommodation may be that the former plant repellents serve as attractants for feeding and/or oviposition for the insect or provide some other benefit. One example is the already mentioned glucosinolates. Larvae of the black swallowtail (Papilio polyxenes) feed exclusively on carrot leaves. If the carrot leaves are infiltrated with allylglucosinolate (sinigrin), the feeding rate and thus the butterfly's growth efficiency is drastically reduced depending on the amount of sinigrin present; at higher concentrations intoxication and death of the larvae occurs (32). The southern armyworm (Spodoptera eridania) is a general feeder, but it prefers the leaves of the lima bean. If these are infiltrated with sinigrin, this insect tolerates the toxicant to a certain extent; but at higher concentrations, far above those of the black swallowtail, its growth is also reduced (32). The cabbage butterfly (Pieris rapae) is an adapted feeder on the sinigrin-containing cabbage and it has overcome the glucosinolate's toxicity, as shown by the constant growth at increasing concentrations of sinigrin (32). This shows once again the relative deterrency of a plant constituent. The cabbage butterfly, however, is not only adapted, but it needs the allylglucosinolate as it only oviposits on plants which contain sinigrin; furthermore, the newly emerging larvae need this compound as a feeding stimulus (13).<smiles>CNCCc1c[nH]c2ccc(O)cc12</smiles>

$N$-methyl serotonine 1<smiles>NC1=NC=NC2C1N=CN2c1ccccc1</smiles>

adenosine 0.5<smiles>COc1c(O)c(C(Cl)(Cl)Cl)c(O)c2c(=O)cc(-c3ccc(O)cc3)oc12</smiles>

vicenin-2 30<smiles>COc1cc(O)c2c(c1)OC(c1ccc(O)c(O)c1)CC2=O</smiles>
\begin{tabular}{ll} 
narirutin & 1.5 \\
\hline (hesperidin) & 15 \\
\hline
\end{tabular}

Scheme D

The same is true for Papilio xuthus. This swallowtail feeds exclusively during its larval stage on Rutaceae, for instance on Citrus unshiu. Females, before depositing their eggs, vigorously drum the leaf surface with their forelegs, thus detecting non-volatile oviposition stimulants of the plant; the females then lay their eggs (33). This was shown artificially by using a filter paper that had been treated with the methanolic extract of Citrus unshiu leaves: the female drums with her forelegs in order to taste the filter paper, then she recognizes the paper as a Citrus leaf and deposits her eggs (33). A series of compounds was detected (Scheme D) which act synergistically and require a definite composition for the most active response (the ratio is given in boxes in Scheme D) (33). This complex mixture obviously specifically indicates the foodplant, and provides an insight into how insects use non-volatile plant secondary substances for their orientation.

\section{Insects Sequester, Accumulate, and Collect Plant Secondary Compounds}

If an insect is adapted to plant constituents that primarily were deterrents, it may itself sequester, accumulate, or collect compounds which are then used as allelochemicals or are metabolized for the insect's benefit.

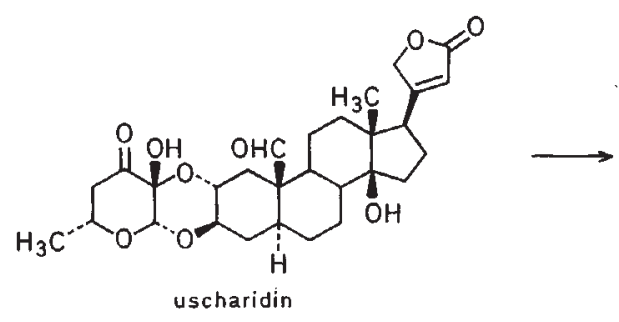

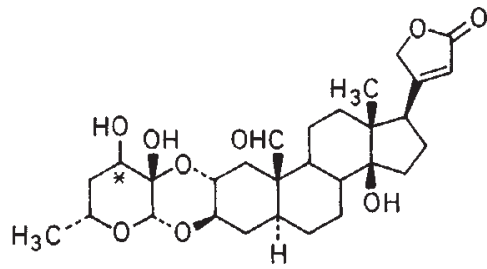

Scheme $\mathbf{E}$

calotropin/calactin

This is true, for example, of the cardenolides which (as shown above) serve as an oviposition deterrent for the black swallowtail. The larvae of the monarch butterfly (Danaus plexippus) feed on certain Asclepiadaceae, thereby sequestering cardenolides from their host plant and accumulating them up to $0.5 \%$ of their dry mass. In many cases this is more than the plant's concentration of cardiac glycosides which is about $0.2 \%(24,34)$. TLC data from the larvae and their individual host show that a selective uptake or metabolism during uptake occurs, as the set of cardiac glycosides (at least the main compounds) of the plant is less polar than those of the predator $(24,34)$. Indeed, it was shown recently that the plant's uscharidin is reduced to the more polar epimeric mixture of calotropin and calactin (Scheme E) by the monarch's larvae (35). This is only one example from these butterflies, but it underlines that not only does a simple sequestration occur, but also metabolism which seems to be correlated with resorption and accumulation of these compounds. The cardenolides obtained by the larvae are transferred to the adult stage and provide the adults with protection: a naive jay that feeds on such butterflies will never eat one again, as severe vomiting is caused by the cardenolides (36); however, some birds have learned to overcome this defense mechanism (37). 
An interesting importance of secondary plant constituents for some insects was detected in the last 15 years. These insects are said to be pharmacophagous if "they search for certain secondary plant compounds directly, take them up, and utilize them for specific purposes, other than primarily metabolism or food plant recognition" (38). In this paper I will refer only to a few aspects of this behaviour; an excellent summary was given recently (39).

Male butterflies belonging to different species of the Nymphalidae and Artiidae ingest pyrrolizidine alkaloids from flower nectar, or by extracting wilted plants or dry plant parts by injecting fluid through their proboscis and subsequently sucking out the various substances $(40,41)$. In doing so the males receive large doses of pyrrolizidines (Scheme F) which are stored at concentrations up to $10 \%$ (dry weight) in their body. In some species, parts of these are used for defense, while another part of the macrocyclic pyrrolizidines, originally obtained from the plants, is metabolized to give pyrrole derivates, such as danaidon, danaidal, and hydroxydanaidal (Scheme F) (39). These serve as pheromones for the males and are presented by some monarch butterflies to the female on expanded abdominal hairpencils during courtship. The female then, usually, accepts copulation depending on the amount of pyrroles presented by the male (42). This clearly shows that a secondary compound is not only used for defense, but can be converted to give infraspecifical contact (arrest) pheromones on which the insect's population is dependent: without the supply of plant pyrrolizidines the butterflies population would be extinct.
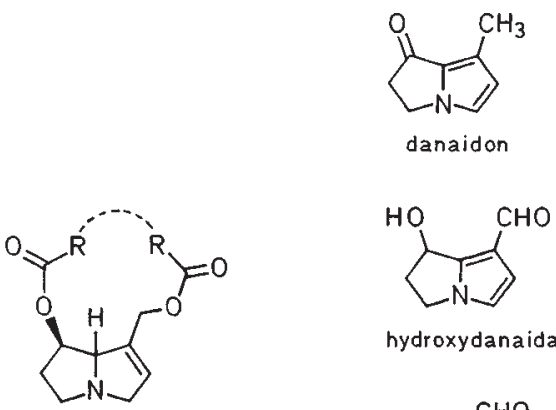

hydroxydanaidal

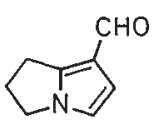

Scheme F

Another insect, the honey bee, uses plant secondary products in another way. The honey bee (Apis mellifica) and other species of bee collect the exudate of poplar leaf buds that contain several flavonoids of which examples are given in Scheme G; additionally, some caffeic acid derivatives are also present $(43,44)$. The composition varies dependent on the source, but in all cases the secretion, so-called propolis, exhibits antibacterial, antifungal, and antiviral activities. The exudates are transported by the bee, without sequestering, into the hive and are used for disinfection of the hive, of dead insects, and of the honeycomb. This behaviour of the bee may be called "pharmacophoric". It indicates that insects have learned to handle normally toxic plant constituents without sequestering and to use them specifically for their own benefit (43).<smiles>O=C1CC(c2ccccc2)Oc2cc(O)cc(O)c21</smiles><smiles>O=C1c2ccc(O)cc2OC(c2ccc(O)c(O)c2)C1O</smiles>

(fisetin)<smiles>O=C(O)/C=C/c1ccc(O)c(O)c1</smiles>

caffeic acid<smiles>COc1ccc2c(=O)cc(-c3ccccc3)oc2c1</smiles><smiles>O=C1/C(=C/c2ccc(O)c(O)c2)Oc2cc(O)ccc21</smiles>

Scheme G

\section{Insects Produce Typical Plant Secondary Products}

It may be advantageous for the insects if they themselves synthesize secondary substances which are usually active plant deterrents (45). Such insects become independent of the host plants and thus can move during evolution to new ecological niches by retaining their chemical defense.

One structural example is provided by the anthraquinones (46). The haemolymph of the larvae of the elm leaf beetle (Pyrrhalta luteola) contains a set of anthraquinones and their corresponding anthrones, two of which are well known constituents of medicinally used plant laxatives (Scheme H). These compounds, as well as the haemolymph containing them, are strongly deterrent against ants such as Iridomyrmex or Monomorium spp. which sometimes inflict wounds upon the larvae, but quickly retreat upon contact with the haemolymph. Since the elm leaves on which they feed do not contain these compounds they are considered to be selfsynthesized by the larvae (45); it is unfortunate that biosynthetic studies have not been undertaken.<smiles>O=C1c2cccc(O)c2C(=O)c2cccc(O)c21</smiles>

1,8-dihydroxyanthraquinone<smiles>O=C1c2c(O)cccc2Cc2cccc(O)c21</smiles>

1,8-dihydroxyanthrone Pyrrhalta luteola (Chrysomelidae)

Scheme H<smiles>Cc1cc(O)c2c(c1)C(=O)c1cccc(O)c1C2=O</smiles>

chrysophanol<smiles>Cc1cc(O)c2c(c1)Cc1cccc(O)c1C2=O</smiles>

chrysophanolanthrone 
The cardioglycosides are typical plant constituents which are not only sequestered but also synthesized by some insects. Some chrysomelid beetles of the genus Chrysolina feed on plants such as rosemary or mint (well known to be free of cardiac glycosides) but nevertheless they contain these compounds in their defense secretion, thereby deriving their protection against predation (47). The three aglycones identified are shown in Scheme I and occur together with their respective xylosides. As such they exhibit all the structural features for cardioactivity. Pasteels and coworkers in Bruxelles have shown recently by feeding carbon-14-labelled precursors, that the beetles themselves produce the glycosides using cholesterol as the biogenetic precursor (48), which they in turn receive from their foodplants, as insects are usually not able to synthesize triterpenoids.<smiles>CC(C)CCCC(C)C12CCC3C(C1)C2CCC1(C)C3CC=C2CC(O)CCC21C</smiles>

cholesterol

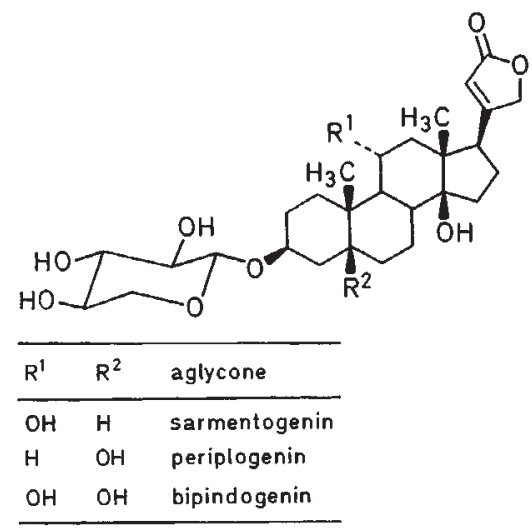

Scheme I

Regarding the biogenetic precursor, these beetles behave like the plants and one may speculate whether this parallelism occurs by chance or is the result of a genetic transfer between the different organisms during coexistence or coevolution within the long period of evolution. Such ideas have already been discussed by Mothes (5) and by others (49), and are supported by the restricted occurrence of more or less complex molecules in very different organisms, such as, for example, lysergic acid derivatives in higher plants and fungi (50), macrocyclic antibiotics and carcinostatics in higher plants and in fungi $(51,52)$, the above-mentioned cardioglycosides, and some cyanogenic glucosides in higher plants and some insects.

\section{Insects Synthesize and Sequester the Same Secondary Compound}

The latter provide us with the last example that stems from our own work on the relationships between plants and insects on the basis of their secondary substances. Several lepidopterans, moths and butterflies, release hydrogen cyanide when injured. One of these is the burnet moth (Zygaena trifolii and related species) and another the neotropical butterfly (Heliconius charitonius and related species). Both (and many others) contain the cyanogenic glucosides linamarin and lotaustralin (Scheme $\mathbf{J}$ ) which are well known from the<smiles>COC(C)(C)C#N</smiles><smiles>CC[C@@](C)(C#N)OC</smiles>

(R)-lotaustralin

Zygaenidae

Heterogynidae

Nymphalidae: Heliconiinae, Nymphatinae, Acraeinae

Lycaenidae: Polyommatinae

Scheme J

plant kingdom [for a summary see Refs. $(53,54)]$. A pretty specific $\beta$-glucosidase responsible for cleaving the cyanoglucosidase has been isolated and characterized from the larvae of Zygaena trifolii (54); a nitrile lyase, catalyzing the quick liberation of cyanide from the comparatively stable products of deglucosylation, the hydroxy nitriles, is currently under investigation; in several Lepidoptera $\beta$-cyanoalanine was detected (56) that is regarded as a product of cyanide detoxification. In all these aspects (substrates, $\beta$-glucosidase, nitrile lyase, $\beta$ cyanoalanine production) these insects closely resemble the plants, in which all these steps are also realized and quite well known (57). Several data indicate that these two glucosides serve as deterrents against several predators. For example, the larvae of Zygaena release a liquid fluid upon irritation that is rich in linamarin and lotaustralin. Irritation also occurs, for instance, by ants, and the ants immediately retreat upon secretion of the fluid (58).

An inspection of the different food plants of these lepidopterans led to the suspicion (53) that biosynthesis of the glucosides may occur in these insects. This was proved by feeding ${ }^{14} \mathrm{C}$-labelled valine and isoleucine as well as the corresponding nitriles, well known from plant biosynthesis as precursors for linamarin and lotaustralin (57). Scheme $\mathbf{K}$ combines the results obtained with some Zygaena spp. and some Heliconiinae: the incorporation rates of ${ }^{14} \mathrm{C}$-labelled precursors from several experiments are up to $7 \%$ for the amino acids and close to $70 \%$ for specific precursors, the nitriles (58). The carbon skeleton is incorporated specifically as was shown by incorporation of ${ }^{13} \mathrm{C}$-enriched amino acids followed by ${ }^{13} \mathrm{C}$-NMR analysis of the products (59). Thus, the production pattern of linamarin and lotaustralin in the lepidopterans is at least similar if not identical to that of higher plants.
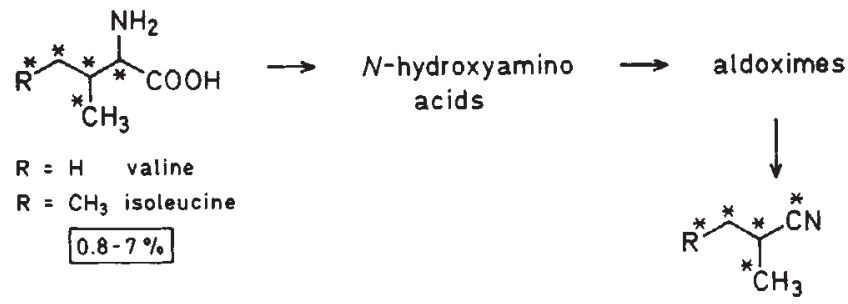

$\mathrm{R}=\mathrm{H}$ isobutyronitrile $\mathrm{R}=\mathrm{CH}_{3}$ 2-methylbutyronitrile $25-70 \%$

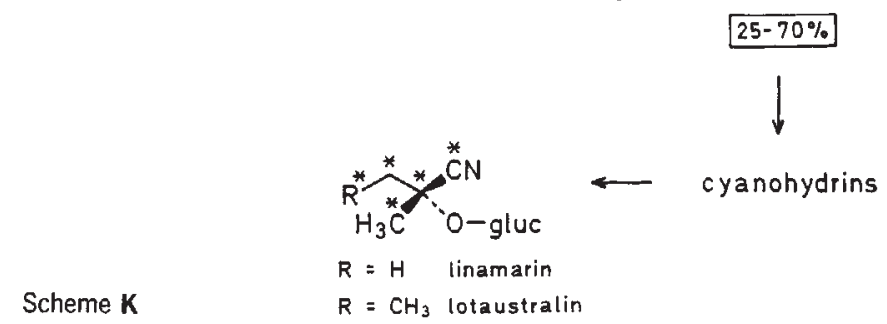


Some Zygaena species feed on Lotus corniculatus (Fabaceae) that contains linamarin and lotaustralin. Some experiments suggested (60) that, in addition to de-novo synthesis, an uptake of both glucosides from the host may occur. Feeding experiments with non-labelled and ${ }^{14} \mathrm{C}$-labelled linamarin and lotaustralin indeed showed that a specific uptake of the glucosides really does occur (60). This result uncovered a hitherto unique situation, namely that an insect is able to sequester from its host the same glucosides which it is also able to synthesize, i.e. an insect synthesizes a compound that it also sequesters from its host. This sequestration behaviour of Zygaena trifolii should have been adapted after development of, and additionally to, biosynthesis, as we know that more primitive Zygaenids, that do not feed on cyanogenic plants, also synthesize these glucosides (53). This last line of plant/insectrelationships represents a high level of adaptation. It may allow the insect to save metabolic energy in the case of a food plant rich in linamarin and lotaustralin and it may be the reason why Zygaena larvae, and the following stages, are extremely rich in these toxic cyanogenic glucosides as compared to other cyanogenic Lepidoptera.

\section{Conclusions}

It is clear that plant secondary substances are highly significant for the interactions between plants and insects, and this becomes more and more obvious as we go through the different levels of adaptation. Although an overview always necessitates a simplification, we may draw the following conclusions. The insects became able during their evolution to handle and to use, and even to produce, plant secondary substances, originally accumulated as deterrents, and plants answered this challenge by chemical diversification of their secondary substances. Unfortunately our knowledge is still based on a limited number of examples particularly concerning biosynthetic data from insects. Although the interactions and relationships between plants and the insects were used for this paper it should be emphasized that the utilization of secondary compounds, primiarily from plants, is a common biological property and it influences strongly the relationships between living organisms, including mankind.

\section{Acknowledgements}

Thanks are due to Prof. Boppré (Freiburg), Prof. Pasteels (Bruxelles), Prof. Schneider (Seewiesen), and Prof. Wollenweber (Darmstadt) for providing information on several topics mentioned; the excellent cooperation with Dr. R. H. Davis (Ashford), Dr. S. Franzl (Münster), Prof. C. M. Naumann (Bielefeld), and Dr. V. Wray (Braunschweig-Stöckheim) is gratefully acknowledged. Victor Wray provided valuable linguistic help.

\section{References}

1 Stahl, E. (1988) Jena. Z. Naturwiss. Med. 22 (N. f. 15), 557.

2 Fraenkel, G. (1959) Science 129, 1466.

${ }^{3}$ Whittaker, R. H., Feeny, P. P. (1971) Science 171, 757.

4 Swain, T. (1977) Ann. Rev. Plant Physiol. 28, 479.

${ }^{5}$ Mothes, K. (1981) Wissenschaft und Fortschritt 30, 413.

${ }^{6}$ Schildknecht, H. (1981) Angew. Chem. 93, 164.

7 Feeny, P. (1983) Curr. Themes Trop. Sci. p. 167.

8 Harborne, J. B. (1986) Nat. Prod. Reports p. 323.

9 Harborne, J. B. (1987) Ann. Bot. 60, 39.

${ }^{10}$ Sondheimer, E., Simeone, J. B. (eds.) (1970) Chemical Ecology, Academic Press, London.

11 Wallace, J. W., Mansell, R. L. (eds.) (1976) Biochemical Interaction Between Plants and Insects, Plenum Press, New York
12 Rosenthal, G. A., Janzen, D. H. (eds.) (1979) Herbivores: Their Interaction with Secondary Plant Metabolites, Academic Press, London.

13 Harborne, J. B. (1982) Introduction to Ecological Biochemistry, Academic Press, London.

14 Schlee, D. (1986) Ökologische Biochemie, Springer, Berlin.

15 Janzen, D. H. (1981) in: Physiological Ecology (Townsend, C. R., Calow, P., eds.), pp. 145-164, Blackwell Sci. Publ., Oxford.

16 Wink, M. (1988) Theor. Appl. Genet. 75, 225.

17 Hall, I. H., Lee, K. H., Starnes, C. O., Sumida, Y., Wu, R. Y., Wadell, T. G., Cochran, J. W., Gerhart, K. G. (1979) J. Pharm. Sci. 68, 537.

18 Gonzalez, A. G., Darias, V., Alonso, G., Boada, J. W., Feria, M. (1978) Planta Med. 33, 356.

19 Isman, M. B., Rodriguez, E. (1983) Phytochemistry 22, 2709.

20 Arnason, J. T., Isman, M. B., Philogene, B. J. R. (1987) J. Nat. Prod. 50,690 .

21 Picman, A. K., Rodriguez, E., Towers, G. N. H. (1979) Chem. Biol. Interact. 28,83 .

22 Towers, G. N. H. (1984) Can. J. Bot. 62, 2900.

23 Rothschild, M., Alborn, H., Stenhagen, G., Schoonhoven, L. M. (1988) Phytochemistry 27, 101

${ }^{24}$ Roeske, C. N., Seiber, J. N. (1976) in: Ref. (11), p. 93ff.

25 Duffey, S. S., Scudder, G. G. E. (1974) Can. J. Zool. 52, 283.

26 Vaughan, G. L., Jungreis, A. M. (1977) J. Insect Physiol. 23, 585.

27 Moore, L. V., Scudder, G. G. E. (1985) J. Insect Physiol. 31, 27.

28 Beerenbaum, M. (1983) Evolution 37, 163.

29 Ivie, G. W., Bull, D. L., Beier, R. C., Pryor, N. W., Oertli, E. H. (1983) Science 221, 374.

${ }^{30}$ Gibson, R. W., Pickett, J. A. (1983) Nature 302, 608.

31 Toong, Y. C., Schooley, D. A., Baker, F. C. (1988) Nature 333, 170.

32 Blau, P. A., Feeny, P., Contardo, L. (1978) Science 200, 1296.

${ }^{33}$ Nishida, R., Ohsugi, T., Kokubo, S., Fukami, H. (1987) Experientia 43,342 .

${ }^{34}$ Martin, R. A., Lynch, S. P. (1988) J. Chem. Ecol. 14, 295.

35 Marty, M. A., Kreiger, R. I. (1984) J. Chem. Ecol. 10, 945

${ }^{36}$ Brower, L. P. (1969) Scientific American 220, 22.

37 Fink, L. S., Brower, L. P. (1981) Nature 291, 67.

38 Boppre, M. (1986) Naturwissenschaften 73, 17.

39 Schneider, D. (1986) in: Perspectives in Chemoreception and Behaviour (Chapman, R. F., Bernays, E. A., Stoffolano, J. G., eds.), pp. 123-141, Springer, New York.

40 Goss, G. J. (1979) Environ. Entomol. 8, 487.

41 Boppre, M. (1981) Ecol. Entomol. 6, 449.

${ }^{42}$ Boppre, M. (1984) in: The Biology of Butterflies (Vane-Wright, R. I., Ackery, P. R. eds.), pp. 259-275, Academic Press, London.

${ }^{43}$ König, B., Dustmann, J. H. (1988) Naturwiss. Rdsch. 41, 43.

${ }^{44}$ Hashimoto, T., Tori, M., Asakawa, Y., Wollenweber, E. (1988) Z. Naturforsch. $43 c, 470$.

45 Nahrstedt, A. (1982) Planta Med. 44, 2.

46 Howard, D. F., Phillips, D. W., Jones, T. H., Blum, M. S. (1982) Naturwissenschaften $69,91$.

47 Pasteels, J. M., Daloze, D., Van Dorsser, W., Roba, J. (1979) J. Comp. Biochem. Physiol. 63c, 117.

${ }^{48}$ Van Oycke, S., Braekman, J. C., Daloze, D., Pasteels, J. M. (1987) Experientia 43,460 .

49 Lewin, R. (1982) Science 217, 42.

${ }^{50}$ Luckner, M. (1984) Secondary Metabolism in Microorganisms, Plants and Animals, p. 395, Springer, Berlin.

51 Jarvis, B. B., Midiwo, J. O. (1988) J. Nat. Prod. 51, 736.

52 Nahrstedt, A. (1984) in: Fortschritte der Arzneimittelforschung (Oelschläger, H., ed.), p. 113, Wissenschaftl. Verl. Ges., Stuttgart.

53 Davis, R. H., Nahrstedt, A. (1985) in: Comprehensive Insect Physiology, Biochemistry and Pharmacology (Kerkut, G. A., Gilbert, L. I., eds.), Vol. 11, pp. 635-654, Pergamon Press, Oxford.

${ }^{54}$ Nahrstedt, A. (1987) Dtsch. Apoth. Z. 127, 2385.

${ }^{55}$ Franzl, S., Nahrstedt, A. (1988) Planta Med. 55, 221; Experientia, in press..

56 Witthohn, K., Naumann, C. M. (1984) Z. Naturforsch. 39c, 837.

57 Conn, E. E. (1980) in: Secondary Plant Products (Encycl. Plant Physiol. N. S. Vol. 8), (Bell, E. A., Charlwood, B. V., eds.), pp. 461492, Springer, Berlin.

58 Nahrstedt, A. (1988) in: Cyanide Compounds in Biology (Ciba Found, Symp. No. 140), pp. 131-150, Wiley, Chichester.

59 Wray, V., Davis, R. H., Nahrstedt, A. (1983) Z. Naturforsch. 38c, 583.

${ }^{60}$ Nahrstedt, A., Davis, R. H. (1968) Phytochemistry 25, 2299. 